American Journal of Applied Sciences 3 (8): 1967-1969, 2006

ISSN 1546-9239

(C) 2006 Science Publications

\title{
Earth-To-Space Improved Model for Rain Attenuation Prediction at Ku-Band
}

\author{
${ }^{1}$ Mandeep Singh Jit Singh, ${ }^{1}$ Hassan,S.I.S, ${ }^{1}$ Ain,M.F, ${ }^{1}$ Ghani, F, ${ }^{2}$ Kiyoshi Igarashi, ${ }^{2}$ Kenji Tanaka and \\ ${ }^{3}$ Mitsuyoshi lida \\ ${ }^{1}$ Universiti Sains Malaysia, Engineering Campus, 14300 Nibong Tebal, Perai Selatan, \\ Pulau Pinang, Malaysia \\ ${ }^{2}$ National Institute of Information and Communications, Technology , 4-2-1, Nukui-kita, \\ Koganei, Tokyo, Japan \\ ${ }^{3}$ Association of Radio Industries and Businesses,1-4-1, Kasumigaseki,Chiyoda-ku, Tokyo, Japan
}

\begin{abstract}
A model for predicting rain attenuation on earth-to-space was developed by using the measurement data obtained from tropical and equatorial region. The proposed rain attenuation model uses the complete rainfall rate cumulative distribution as input data. It was shown that significant improvements in terms of prediction error over existing attenuation model obtained.
\end{abstract}

Keywords: Rain attenuation, earth-to-space, rainfall rate, cumulative distribution

\section{INTRODUCTION}

Rain attenuation modeling on satellite paths have been done by many researchers over the last three decades. With the introduction of Ku-band satellite communication services in the tropical and equatorial region, prediction of rain attenuation has become an important factor. Several empirical and non-empirical rain attenuation prediction models that have been developed are based on the measurement data obtained from temperate regions. Most of these existing rain attenuation prediction models do not appear to perform well in high rainfall regions [1-3]. The ITU-R [4] model is currently being widely used by many researchers. Cumulative distribution empirical evidence [5] shows that the ITU-R model underestimates the measured rain attenuation cumulative distribution when applied to tropical regions, leading to a poor prediction. Therefore in this letter, a modified ITU-R model was developed using the complete rainfall rate cumulative distribution and the horizontal path length to calculate the cumulative distribution of rain attenuation for tropical and equatorial regions.

Experimental setup: The receiver sites are located at University Sains Malaysia (USM), King Mongkut's Institute of Technology Ladkrabang (KMITL) and Indonesia Institute Technology Bandung (ITB). Descriptions of the measurement sites are presented in Table 1.
Table 1: Measurement Sites Characteristics

\begin{tabular}{|c|c|c|c|}
\hline $\begin{array}{c}\text { Measurement } \\
\text { Site }\end{array}$ & USM & KMITL & ITB \\
\hline $\begin{array}{c}\text { Earth Station } \\
\text { Location }\end{array}$ & $\begin{array}{c}5.17^{0} \mathrm{~N} \\
100.4^{0} \mathrm{E}\end{array}$ & $\begin{array}{c}13.7^{0} \mathrm{~N} \\
100.8^{0} \mathrm{E}\end{array}$ & $\begin{array}{c}6.5^{0} \mathrm{~S} \\
107.4^{0} \mathrm{E}\end{array}$ \\
\hline $\begin{array}{c}\text { Beacon } \\
\text { Frequency, } \\
(\mathrm{GHz})\end{array}$ & 12.255 & 12.74 & 12.247 \\
\hline $\begin{array}{c}\text { Antenna } \\
\text { Elevation } \\
\text { (deg) }\end{array}$ & 40.1 & 54.8 & 64.7 \\
\hline Altitude (m) & 57 & 40 & 700 \\
\hline $\begin{array}{c}\text { Antenna } \\
\text { Diameter (m) }\end{array}$ & 2.4 & 2.4 & 1.8 \\
\hline
\end{tabular}

The receiver antennas are pointed towards SUPERBIRD-C located at $144^{0} \mathrm{E}$ for USM and JCSAT-1B located at $128^{\circ} \mathrm{E}$ for KMITL and ITB. The SUPERBIRD-C and JCSAT-1B are highly reliable three-axis stabilized spacecraft with a transponder RF output power of $90 \mathrm{~W}$ and $60 \mathrm{~W}$ respectively at $\mathrm{Ku}$-Band. The orientation of the receiver antennas is horizontal polarized. Simultaneous rain rate were measured by a tipping bucket rain gauge with a sensitivity of $0.5 \mathrm{~mm}$ per tip. The integration time used for computation of the rain rate is $1 \mathrm{~min}$. The total acquisition time was above $96 \%$ during the 24 months of measurement.

\footnotetext{
Corresponding Author: $\quad$ Mandeep Singh Jit Singh. School of Electrical and Electronic Engineering, University Sains Malaysia, Engineering Campus, 14300 Nibong Tebal,Seberang Perai Selatan, Pulau Pinang, Malaysia
} 
RAIN ATTENUATION PROPOSED MODEL: The modified ITU-R model retains the concept of an equivalent rain cell. The horizontal projection of the slant path, $L_{G}$ was modified based on the rain height, elevation angle, reduction factor, and the rainfall rate at the measurement sites. Therefore this model was revised, so that it can be used at tropical countries with the antenna elevation angle varying from $40^{\circ}$ to $70^{\circ}$. In the ITU-R model, the rainfall rate exceeded at $0.01 \%$ of time is used for predicting the correspondent value of rain attenuation. The extrapolation formula was also used to calculate the rain attenuation exceeded at other percentages of time between $1 \%$ and $0.001 \%$. In the proposed model, the extrapolation formula was modified based on the rain attenuation data obtained from the measurement sites. The rain attenuation exceeded during $P \%$ of time is then given by:

$A_{P}=A_{0.01} * 0.12 * P^{-(0.58569+0.061046 \log (P))} \mathrm{dB}$

where $\mathrm{A}_{0.01}$ is the rain attenuation exceeded at $0.01 \%$ of time.

The specific attenuation, $\gamma$ is a function of the rainfall rate, $R_{0.01}$ exceeded at $0.01 \%$ of time is given by:

$\gamma=k\left(R_{0.01}\right)^{\alpha} \quad \mathrm{dB} / \mathrm{km}$

where $k$ and $\alpha$ are frequency and polarization parameters, given by ITU-R recommendation [6].

The horizontal reduction factor, $r_{0.01}$ exceeded at $0.01 \%$ of time is given by:

$r_{0.01}=\left[1+L_{G} / L_{o}\right]^{-1}$

where $L_{o}$ is equivalent rain cell length and $L_{G}$ is horizontal projection of the slant path calculate by using the rain attenuation data at the measurement site. This parameter is given by:

$L_{G} \quad=-3167.9714+2088.3369[$

$\left.L_{S} \operatorname{Cos}(\theta)\right]-$

$66.345562\left[L_{S} \operatorname{Cos}(\theta)\right]^{2}$

$2182.7255\left(\ln \left[L_{S} \operatorname{Cos}(\theta)\right]\right)^{2}+1229.5222 \quad / \quad\left[L_{S} \operatorname{Cos}(\theta)\right]^{2}$ $\mathrm{km}$

where $L_{S}$ is the slant path length and $\theta$ is the antenna elevation angle.

The rainfall attenuation, $A_{0.01}$ exceeded at $0.01 \%$ of time is given by:

$A_{0.01}=\gamma * r_{0.01} * L_{S} \quad \mathrm{~dB}$
Fig.1, Fig.2 and Fig.3 shows the scatter plot of the measured rain attenuation and the proposed rain attenuation model. From these figures, it can be seen that there is high correlation between the measured data and the proposed model.

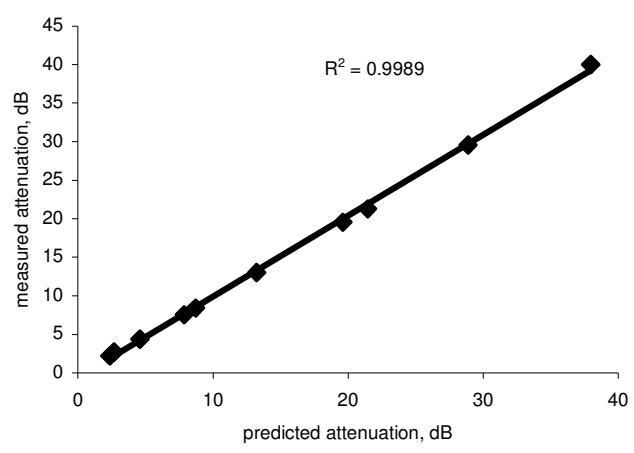

Fig.1: Scatter plot of Measured and Proposed

Attenuation Values for USM

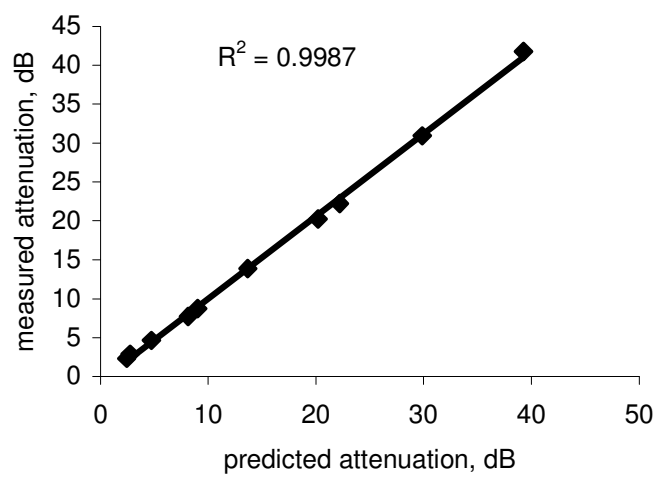

Fig.2: Scatter plot of Measured and Proposed

Attenuation Values for KMITL

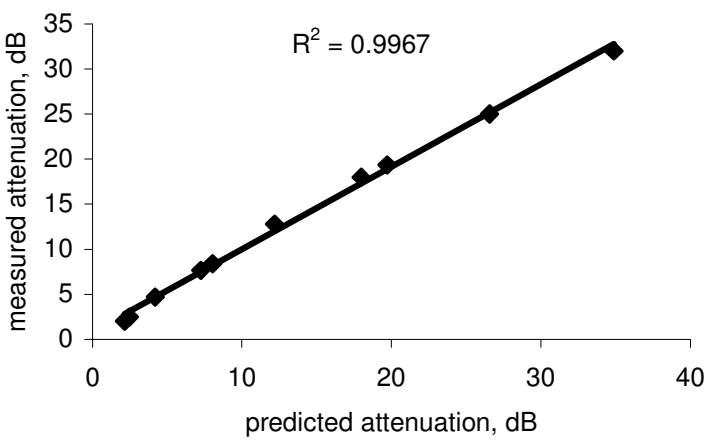

Fig.3: Scatter plot of Measured and Proposed

Attenuation Values For ITB 
Am. J. Applied Sci., 3 (8): 1967-1969, 2006

Table 2: Percentage error and RMS values of test variable for USM, KMITL and ITB

\begin{tabular}{|c|c|c|c|c|c|c|c|c|c|}
\hline & $P \%$ & 0.001 & 0.003 & 0.01 & 0.03 & 0.1 & 0.3 & 1 & \\
\hline \multirow{3}{*}{ USM } & & & & & & & & & $\%$ RMS \\
\hline & ITU & -27.9 & -18.1 & -6.4 & 0.4 & 6 & 9.1 & -26.4 & 16.2 \\
\hline & Proposed & -5.1 & -2.4 & 0.05 & 1.1 & 4.32 & 4.17 & 8.19 & 2.9 \\
\hline \multirow[t]{2}{*}{ KMITL } & ITU & -40.3 & -33.4 & -23 & -18.1 & -12 & -15.1 & -41.3 & 28.4 \\
\hline & Proposed & -6.09 & -3.63 & -0.49 & -1.46 & 5.78 & 1.94 & 5.81 & 4.11 \\
\hline \multirow[t]{2}{*}{ ITB } & ITU & -35.5 & -29 & -23.3 & -17.9 & -22 & -18.3 & -48.1 & 29.9 \\
\hline & Proposed & 9 & 6.19 & -0.11 & -4.92 & -5.4 & -1.56 & 6.79 & 6.14 \\
\hline
\end{tabular}

COMPARISON WITH ITU-R: The proposed model was tested against the ITU-R method using test suggested by ITU-R [7]. The test variable for percentage error and RMS values are given by:

$$
\mathrm{E}_{\mathrm{rel}}=\left[\left(A_{\text {predicted }}-A_{\text {measured }}\right) / A_{\text {measured }}\right] \times 100
$$

where $A_{\text {predicted }}$ and $A_{\text {measured }}$ are the predicted and measured rain attenuation values exceeded at a given percentage of time.

The mean error, $\mu_{e}$ and standard deviation, $\sigma_{e}$ are used to calculate the Root Mean Square, $D_{e}$ (RMS). The parameter is defined as follows

$$
D_{e}=\left[\left(\mu_{\mathrm{e}}\right)^{2}+\left(\sigma_{e}\right)^{2}\right]^{1 / 2}
$$

According to evaluation procedures adopted by the CCIR the preferred prediction method is the one producing the smallest RMS values [7].

Table 2 shows the comparison in terms of percentage error and RMS values between the proposed model and the ITU-R model for USM, KMITL and ITB. It can be seen that the proposed model shows a significant improvement in terms of prediction error and RMS values over the ITU-R attenuation model for all the three measurement sites.

\section{CONCLUSION}

The proposed rain attenuation model for earth-tospace performed better than the ITU-R model. The model can be used for different elevation angles and it is simply to use.

\section{ACKNOWLEDGEMENT}

We are grateful to USM, KMITL, ITB and the Ministry of Public Management, Home Affairs, Posts and Telecommunication Japan (POST-PARTNERS) for supporting this research.

\section{REFERENCES}

1 Dissanayake, A.W., Allnutt, J.E., Haidara, F. 1997. A prediction model that combines rain attenuation and other propagation impairments along Earth-satellite paths'. IEEE Transactions on Antenna and Propagation, 45 (10), pp:1546-1557

2 Dissanayake, A.W. and Allnutt, J.E. 1992. Prediction of rain attenuation in low-latitude regions'. Proceedings of URSI Open Symposium on Wave Propagation and Remote Sensing,, North Yorkshire, Vol.6, pp:6.4.1-6.4.6

3 Perez Garcia, N.A. and Silva Mello, L.A.R. 2004. Improved method for prediction of rain attenuation in terrestrial links'. Electronic Letters, 40, (11), pp. 847-848

4 CCIR Document 5C/TEMP/13 1991. Draft modification to Recommendation 618: 'Propagation data required for earth-space telecommunication system'. December, Geneva

5 Ong.J.T. and Zhu,C.N. 1997. Slant path attenuation at $11 \mathrm{GHz}$ in Singapore'. Electronic Letters, 33, (13), pp.1178-1179

6 CCIR Report 721-3. 1990 Attenuation by hydrometeors, in particular precipitation, an other atmospheric particles' Dusseldorf

7 CCIR documents 5/176 1983 'Working group'. 5-D. Geneva 